\title{
The Emergence of Precision Urologic Oncology: A Collaborative Review on Biomarker-driven Therapeutics
}

\author{
Christopher E. Barbieri ${ }^{a, b,{ }^{\star}}$, Arul M. Chinnaiyan ${ }^{c}$, Seth P. Lerner ${ }^{d}$, Charles Swanton ${ }^{\mathrm{e}}$, and \\ Mark A. Rubin ${ }^{a, b, f}$ \\ a Department of Urology, Weill Cornell Medical College, New York, NY, USA \\ b Sandra and Edward Meyer Cancer Center of Weill Cornell Medical College, New York, NY, USA \\ ${ }^{c}$ Michigan Center for Translational Pathology, Departments of Pathology and Urology, and \\ Howard Hughes Medical Institute, University of Michigan Medical School, Ann Arbor, MI, USA \\ d Scott Department of Urology, Baylor College of Medicine, Houston, TX, USA \\ e University College London Cancer Institute, Cancer Research UK Lung Cancer Centre of \\ Excellence, London, UK \\ ${ }^{f}$ Englander Institute for Precision Medicine, Weill Cornell Medical College, New York, NY, USA
}

\begin{abstract}
Context-Biomarker-driven cancer therapy, also referred to as precision oncology, has received increasing attention for its promise of improving patient outcomes by defining subsets of patients more likely to respond to various therapies.
\end{abstract}

\footnotetext{
* Corresponding author. Weill Medical College of Cornell University, Urology, 525 East 68th Street, Starr 900, New York, NY 10065, USA. Tel. +12127465562; Fax: +1212 746 0975. chb9074@ med.cornell.edu (C.E. Barbieri).

Publisher's Disclaimer: This is a PDF file of an unedited manuscript that has been accepted for publication. As a service to our customers we are providing this early version of the manuscript. The manuscript will undergo copyediting, typesetting, and review of the resulting proof before it is published in its final citable form. Please note that during the production process errors may be discovered which could affect the content, and all legal disclaimers that apply to the journal pertain.

Precision medicine has the highest potential to impact the care of patients, and major strides have been made in urologic oncology. Prospective clinical trials will define reliable predictive biomarkers and new therapeutic targets leading to real improvement in patient outcomes.
}

Author contributions: Christopher E. Barbieri had full access to all the data in the study and takes responsibility for the integrity of the data and the accuracy of the data analysis.

Study concept and design: Barbieri, Chinnaiyan, Lerner, Swanton, Rubin.

Acquisition of data: Barbieri.

Analysis and interpretation of data: Barbieri, Chinnaiyan, Lerner, Swanton, Rubin.

Drafting of the manuscript: Barbieri, Chinnaiyan, Lerner, Swanton, Rubin.

Critical revision of the manuscript for important intellectual content: Barbieri, Chinnaiyan, Lerner, Swanton, Rubin.

Statistical analysis: None.

Obtaining funding. Barbieri, Chinnaiyan, Lerner, Swanton, Rubin

Administrative, technical, or material support: Barbieri, Chinnaiyan, Lerner, Swanton, Rubin.

Supervision: Rubin.

Other: None.

Financial disclosures: Christopher E. Barbieri certifies that all conflicts of interest, including specific financial interests and relationships and affiliations relevant to the subject matter or materials discussed in the manuscript (eg, employment/affiliation, grants or funding, consultancies, honoraria, stock ownership or options, expert testimony, royalties, or patents filed, received, or pending), are the following: Barbieri is a Damon Runyon Clinical Investigator supported (in part) by the Damon Runyon Cancer Research Foundation. 
Objective-In this collaborative review article, we examine recent literature regarding biomarker-driven therapeutics in urologic oncology, to better define the state of the field, explore the current evidence supporting utility of this approach, and gauge potential for the future.

Evidence acquisition-We reviewed relevant literature, with a particular focus on recent studies about targeted therapy, predictors of response, and biomarker development.

Evidence synthesis-The recent advances in molecular profiling have led to a rapid expansion of potential biomarkers and predictive information for patients with urologic malignancies. Across disease states, distinct molecular subtypes of cancers have been identified, with the potential to inform choices of management strategy. Biomarkers predicting response to standard therapies (such as platinum-based chemotherapy) are emerging. In several malignancies (particularly renal cell carcinoma and castration-resistant prostate cancer), targeted therapy against commonly altered signaling pathways has emerged as standard of care. Finally, targeted therapy against alterations present in rare patients (less than $2 \%$ ) across diseases has the potential to drastically alter patterns of care and choices of therapeutic options.

Conclusions-Precision medicine has the highest potential to impact the care of patients. Prospective studies in the setting of clinical trials and standard of care therapy will help define reliable predictive biomarkers and new therapeutic targets leading to real improvement in patient outcomes.

Patient summary-Precision oncology uses molecular information (DNA and RNA) from the individual and the tumor to match the right patient with the right treatment. Tremendous strides have been made in defining the molecular underpinnings of urologic malignancies and understanding how these predict response to treatment - this represents the future of urologic oncology.

\section{Keywords}

Precision Medicine; Mutations; Sequencing; Genomics

\section{Introduction}

The past decade has seen an explosion of therapeutic options in urologic oncology, across multiple cancer types. Renal cell carcinoma (RCC) patients now have options of tyrosine kinase inhibitors, mechanistic target of rapamycin (mTOR) inhibitors, and immunotherapy agents. The prostate cancer field has seen the approval of over half a dozen novel agents in the past few years, as well as shifting paradigms regarding the temporal sequencing of agents $[1,2]$. Urothelial carcinoma, in addition to defining subsets of patients with best response to standard of care chemotherapeutic options, appears poised for novel agents to make meaningful impact as well. Clearly, this is an exciting time to be in urologic oncology, as there is more promise and hope for our patients than ever before.

Each novel therapy improves outcomes compared with previous generations of standard therapy, but unfortunately, the recent improvements in patient survival can be described as incremental rather than transformative. However, defined subsets of patients respond well to each therapy, and it is likely that these subsets of responders are not the same for all different 
therapeutic options. The example of trastuzumab (Herceptin) in breast cancer treatment may serve as a model for successful development of precision medicine approaches. Trastuzumab was the first rationally designed targeted therapy for solid tumors, based on the discovery that some breast cancers have a high degree of amplification of Her2/neu [3], and that these cancers are associated with worse prognosis [4]. Development of the drug from bench to approval spanned $13 \mathrm{yr}$ - and it has now been responsible for a dramatic change in outcome for women for this subtype of breast cancer.

In urologic oncology, now comes the challenge of taking these diverse therapeutic opportunities, and finding ways to match the right therapy with the right patient: the paradigm of precision medicine. In this review we will explore the history, challenges, and opportunities inherent in this process, and explore the future of biomarker-driven therapeutics in urologic oncology.

Biomarker-driven therapy can refer to multiple approaches to patient stratification and selection of management strategies. First, this can refer to classic targeted therapy, in which a specific gene product serves as both the biomarker and the target of therapeutic action$H E R 2$ overexpression in breast cancer, or $B R A F$ mutations in melanoma, are classic examples [5]. Secondly, biomarkers may distinguish patients that are preferentially sensitive (or resistant) to standard therapeutic options, even though these specific biomarkers are not targets themselves (such as triple negative breast cancer or KRAS mutated colorectal cancers). Finally, distinct subclasses of cancers may respond in fundamentally different manners to various therapeutic interventions - many such subclasses may be identifiable using histologic criteria, but others may only be exposed using specific molecular biomarkers. We will review these concepts across urologic oncology in a relatively diseasespecific manner. In addition, we will also discuss issues that apply more universally, across multiple malignancies and multiple signaling pathways. These include concepts of utilizing biomarker-driven stratification to determine sequencing of different therapeutic options, implications of tumor heterogeneity for biomarker-driven therapeutics, and the impact of novel approaches such an immunotherapy.

The foundations this field is based upon have undergone major advances with the advent of novel technologies for molecular profiling of tumor and patient tissue, including nextgeneration sequencing of DNA and RNA, improved understanding and profiling of epigenetics, and advanced proteomic analysis. Biomarkers can be defined using DNA sequencing (targeted or unbiased exome/genome-wide approaches), transcriptome profiling (RNA-sequencing or microarray-based gene expression), and in-situ techniques like immunohistochemistry or RNA in-situ hybridization to define protein and expression and localization [6,7]. Application of these technologies, including systematic studies as part of the International Cancer Genome Consortium and The Cancer Genome Atlas projects, has led to a massive expansion of the catalog of known alterations in urologic oncology, the starting point for defining biomarkers with real relevance for clinical care. 


\section{Evidence acquisition}

Medline and Google Scholar searches were conducted to identify original articles, review articles, editorials, and presented abstracts addressing biomarker driven therapeutics in urologic malignancies. Keywords included "biomarker," "targeted therapy," "predictors of response," "therapy resistance," and "heterogeneity." We limited our initial search to studies and investigations published from January 2005 to January 2016. References cited in selected articles and in review articles retrieved in our search were also used to identify manuscripts that were not included in the initial search. Links to related articles and crossreading of citations in related articles were surveyed. The articles that provided the highest level of evidence were then evaluated and selected with the consensus of authors. A total of 103 articles were reviewed. This collaborative review is the result of an interactive peerreviewing process by the panel of coauthors.

\section{Evidence synthesis}

\subsection{Targeted therapies in urologic oncology}

3.1.1 Androgen signaling in prostate cancer-The oldest form of targeted therapy in urology (and perhaps in all of oncology) came with the recognition that ablation of androgens via surgical castration resulted in regression of advanced prostate cancer. Although not often thought of as targeted therapy, the dependence of prostate cancer on androgen signaling forms the basis of the historical and current approach to advanced prostate cancer, with androgen ablation representing the mainstay of treatment for the disease. The more recent discovery that castration-resistant prostate cancer (CRPC) largely maintains its dependency on androgen signaling further underscores the central importance of this signaling axis, and multiple novel therapeutics rely on improved targeting of androgen signaling over and beyond that which can be achieved using surgical castration or convention androgen-deprivation therapy approaches. These include further reductions of androgen production by targeting synthetic enzymes such as CYP17, the target of abiraterone acetate (Zytiga), and improved inhibition of the androgen receptor itself (enzalutamide/Xtandi, ARN-509/apalutamide) and downstream effects on transcription, proliferation, and survival of prostate cancer cells. These approaches have been reviewed elsewhere $[8,9]$.

A critical question for these next-generation antiandrogen agents going forward is determining the patients that will most benefit from their use. Deregulation of the androgen signaling axis is common in prostate cancer [6], and alterations in the $A R$ gene itself become highly prevalent in CRPC [10]. These include amplification of the $A R$ gene, point mutations, and splice variants. The impact of these alterations on response to antiandrogen therapy remains unclear, and this is a major focus of ongoing clinical and preclinical investigation.

Mutations and gene amplifications in the $A R$ gene itself have long been known to emerge and promote resistance in the setting of conventional androgen ablation [11-13]. However, implications of these genomic events for patient response to newer agents like enzalutamide and abiraterone are less clear, and data has only recently begun to emerge. Several studies 
suggest that $A R$ amplification and mutation are more common in patients progressing on these therapies compared with responders [14], and there are suggestions that amplification of $A R$ can predict response to both enzalutamide and abiraterone [15,16]. Preclinical models have shown that constitutively active, truncated androgen receptor splice variants can continue to drive androgen signaling in CRPC cells, and that this activity can promote resistance to enzalutamide [17]. Clinical studies have also reported that the presence of one such androgen receptor splice variant in circulating tumor cells from patients with CRPC is correlated with resistance to second-generation androgen targeting agents [18], and may emerge during therapy [19]. Across all these questions, larger, rigorously conductive clinical studies and correlative genomic analysis will be necessary to provide definitive answers.

3.1.2 Neuroendocrine prostate cancer-A subset of CRPC transitions from $A R$ dependence to an $A R$ indifferent state. These CRPC-neuroendocrine cancers have been also referred to as neuroendocrine prostate cancer and anaplastic cancer [20,21]. This is a highly aggressive form of CRPC that may emerge in the setting of prolonged androgen-targeting therapy [22]. Improved characterization of this entity at the clinical, histological, and molecular level is ongoing [20]. Currently there are no standard approaches to treating CRPC-neuroendocrine cancers, which are associated with a mean 7-mo survival time. Several groups have now reported altered signaling pathways that may represent therapeutic target options. These include engagement of $\mathrm{N}$-myc signaling and upregulation of aurora kinase A [23] - importantly, aurora kinase A is a druggable target, with clinical trials ongoing. Such studies may define the paradigm of bedside to bench to bedside medicine that can represent the hallmark of biomarker-driven therapy.

3.1.3 RCC—-the VHL/hypoxia inducible factor pathway-RCCs represent a diverse collection of histological subtypes, each with specific subsets of underlying molecular alterations. Clear cell RCC (ccRCC), the most common and among the most aggressive histological variant, is highly associated with inactivation of the tumor suppressor VHL [24]. The $V H L$ gene undergoes inactivation via point mutations, genomic deletions, and gene methylation in ccRCC. The VHL protein normally promotes ubiquitination and degradation of hypoxia inducible factors (HIFs) such as HIF1a and HIF2a, transcription factors that act as key regulators of the hypoxic response. Inactivation of VHL in RCC leads to increased $\mathrm{HIFa}$ expression, and increased activation of targets genes such as $V E G F$ and $P D G F$ [24].

Because of the universality of $V H L$ inactivation and activation of the HIF/vascular endothelial growth factor (VEGF) pathways in RCC, interference with downstream effects of HIF (in particular $V E G F$ and $P D G F$ signaling) emerged as a major focus of drug development and clinical research over the past decade. Approved agents targeting these pathways include bevacizumab (Avastin), a humanized monoclonal antibody that binds VEGF, and orally active inhibitors targeting multiple tyrosine kinases and growth factor receptors (including VEGFR and PDGFR signaling)—-these include sorafenib (Nexavar), sunitinib (Sutent), pazopanib (Votrient), and axitinib (Inlyta). The early trials employing bevacizumab demonstrated proof of principle in human patients that agents inhibiting VEGF signaling could significantly alter tumor progression in RCC $[25,26]$. Since then, antitumor activity of these agents has been well established in a series of phase 3 clinical trials, with 
improvement in both progression-free and overall survival [27-31]. However, molecular predictors of response to these agents remain unclear. Alterations in the VHL-VEGF signaling axis do not perfectly correlate with response [32]. These agents also have activity in nonclear cell histologies of RCC, which classically do not display genomic alterations in these signaling pathways. Clearly, ongoing research has the potential to identify markers that may allow substratification of RCC patients to individualized treatment regimens.

3.1.4 RCC-mTOR Signaling - $m$ TOR is an intracellular kinase that acts as a signaling node in the phosphoinositide 3-kinase (PI3-kinase)/Akt pathway, and functions to coordinate a number of cellular events surrounding growth and energy sensing and regulation, including regulation of protein translation, degradation, and signaling. Like VHL inactivation and upregulation of hypoxia transcriptional programs, activation of the mTOR/PI3K pathway is common in RCC [33]. Genomic alterations in this pathway are relatively uncommon when estimated from a single tumor sample, with mutations in genes such as MTOR, TSC1, PIK3CA, and PTEN occurring in less than 10\% of RCC patients [34]. However, assessment of tumor heterogeneity in RCC and definition of tumor evolution using phylogenetic trees has helped reshape biological understanding and clinical implications of these findings. It is increasingly clear that somatic mutations in the mTOR pathway display clear evidence of intratumor heterogeneity, commonly occurring in some tumor subclones but not others. Somatic mutations in this pathway therefore occur later in tumor evolution than VHL and $3 p$ loss of heterozygosity. Tumor sampling bias inherent to such intratumor heterogeneity hinders approaches to define activation of the mTOR pathway in order to guide therapy $[35,36]$. Inhibitors of mTOR signaling are currently used as standard options for poor risk RCC patients. Initial trials showed activity of temsirolimus in RCC, improving both PFS and OS compared with interferon-a $[37,38]$. Further analyses suggested activity in both ccRCC and other subtypes, and temsirolimus was subsequently approved for therapy of advanced RCC. The oral agent everolimus was shown to improve survival compared with placebo in patients with progressive disease after tyrosine kinase inhibitor therapy [39], and is currently being evaluated as an adjuvant therapy for patients at increased risk for progression following radical nephrectomy (NCT 01120249). These mTOR-directed therapies continue to be a mainstay of the armentarium in advanced RCC. In addition, mTOR inhibition has emerged as a standard therapy in renal angiomyolipoma [40,41], consistent with the critical role of the tuberous sclerosis complex-mTOR pathway in the pathogenesis of these lesions [42].

3.1.5 Targeted therapy—conclusions-In general, the targeted agents described above -in both prostate cancer and RCC examples-improve patient survival compared with prior generations of therapy, while at the same time displaying milder toxicity profiles. However, they do not represent curative therapies - complete responses are highly uncommon, and the survival advantages displayed are measured in months, not years. Additional studies and clinical trials are still needed to improve current practice and better understand predictors of response, sequencing of agents, and comparative efficacy of the current agents. 


\subsection{Predictors of response to standard of care therapies}

The definition of biomarkers that can predict the success or failure of standard of care therapies is one of the most important areas of active research in urologic oncology. This has the potential for major impact on patients' lives by enriching treated patients for those likely to respond, improving the overall response rates for therapies with limited response rates overall (but dramatic response in a subset of patients), and allowing patients with a low likelihood of response to move on to other lines of treatment or to clinical trials.

\subsubsection{Predictors of response to platinum chemotherapy in urothelial cancer-} Perhaps the most impressive recent example of this paradigm in urology is predictors of response to platinum chemotherapy in urothelial cancer. Level I evidence supports the utility of platinum-based chemotherapy regimens in the metastatic [43] and neoadjuvant settings $[44,45]$. In the neoadjuvant setting, methotrexate, vinblastine, Adriamycin, and cisplatin and other regimens have shown improved overall survival compared with radical cystectomy alone $[44,45]$. However, the absolute increase in overall survival is small (about $5 \%$ at $5 \mathrm{yr}$ ) based on meta-analyses [46-48], leading many to question the general application of the neoadjuvant approach to all patients with muscle invasive bladder cancer [49]. Importantly, patients who show complete response of the primary tumor (pT0N0 at cystectomy) appear to have the most major benefit in terms of overall survival.

It is clear that not all patients benefit from cisplatin-containing chemotherapy regimens, and morbidity is not trivial, but a minority of patients has a striking (and possibly curative) response. Therefore, defining the subset of patients and tumors likely to respond could have major impact [49]. Many studies in the past have examined candidate predictive biomarkers for cisplatin response-results have been mixed, and despite decades of research, no biomarkers to date have shown adequate predictive value to be currently utilized in the clinic [50]. However, the recent advent of next-generation technologies for unbiased, genome-wide molecular profiling of cancers has renewed hope for defining these biomarkers. Van Allen and colleagues [51] performed whole-exome sequencing on pretreatment muscle-invasive urothelial carcinoma from a defined set of patients with either a complete pathologic response/residual carcinoma in situ only or persistent muscle invasive cancer following cisplatin-based neoadjuvant chemotherapy. They identified somatic mutations in ERCC2, a component of the nucleotide excision repair system, as occurring preferentially in responders. Similarly, Plimack et al [52] showed that lesions in DNA repair genes ATM, $R B 1$, and $F A N C C$ predicted pathologic response to neoadjuvant cisplatin. Others have reported alterations in genes affecting other DNA repair pathways as potentially important for prognosis, reinforcing this theme [53,54].

Other studies have revealed different potential biomarkers of response to platinum-based chemotherapy regimens. Utilizing targeted sequencing of urothelial carcinoma (muscle invasive and metastatic tumors) from patients treated with platinum-based chemotherapy regimens, Groenendijk and colleagues [55] reported that ERBB2 mutations were associated with improved response to neoadjuvant chemotherapy. The Southwest Oncology Group has initiated an intergroup clinical trial to validate the COXEN algorithm as a predictive marker for response to neaodjuvant chemotherapy prior to radical cystectomy (NCT 02177695). If 
validated, a phase 3 trial will be initiated to evaluate COXEN-directed neoadjuvant chemotherapy. Finally, distinct subtypes of bladder cancer have also been identified at the molecular level, including basal and luminal subtypes (similar to breast cancer) and a chemoresistant subtype with a distinct signature of p53 activation [56]. Heterogeneity at the level of tumor itself, stage of disease, patient characteristics, and treatment variability, complicate interpretation of these studies across cohorts, and necessitate extensive validation in well-annotated and more homogeneous patient cohorts. Further prospective data will be necessary to integrate all these findings, and most importantly, define the true clinical utility of any markers in practice.

3.2.2 CRPC and DNA repair in prostate cancer-A recent landmark study exposes the molecular underpinnings of CRPC and provides unprecedented insight to biology and mechanisms of therapy resistance in this disease. The SU2C/PCF Prostate Dream Team performed comprehensive molecular characterization of the metastatic tumors in 150 men with CRPC, revealing a high degree of actionable events, including frequent alterations in $A R$ and $P I 3 K$ signaling [10]. Furthermore, nearly $20 \%$ of CRPC samples harbored somatic genomic lesions in components of DNA repair pathways (such as BRCA2, BRCA1, and $A T M$ ). This is especially timely given the recent emergence of polyadenosine diphosphate ribose polymerase inhibitors as therapeutic options for patients with DNA repair deficient cancers. A phase 2 trial of the polyadenosine diphosphate ribose polymerase inihibitor olaparib in metastatic CRPC showed patient responses specifically associated with defects in DNA repair pathways [57], with further trials ongoing. Platinum agents are reported to have similar activity in this patient population [58]. Furthermore, emerging data also suggest that CRPC patients have a surprising prevalence of germline defects in DNA repair genes (eg, $B R C A$ carriers), expanding the potential impact [59].

\subsection{Immunotherapy}

Urologic malignancies have a relatively long history of successful treatment with agents modulating the immune response to tumors. These include the standard of care use of bacillus Calmette-Guérin in urothelial cancer, and application of agents such as IL-2 and interferon in the armamentarium against RCC [60,61]. Interestingly, like many therapies, there appears to be specific subsets of patients with robust and often durable responses to these agents [62-64]. Newer approaches that have focused on the inhibition of immune checkpoint molecules that can restrict antitumor immune responses have also shown promise. Therapy targeting the cytotoxic T-lymphocyte-associated protein 4 T-cell checkpoint receptor (eg, ipilumimab) has shown some suggestion of response in prostate cancer clinical trials. In RCC, limited human trials have shown potentially impressive response rates using agents targeting the programmed cell death protein-1/programmed death-ligand 1 (PD-L1) interaction [65]. Both anticytotoxic T-lymphocyte-associated protein 4 and programmed cell death protein-1/PD-L1 therapy are under active investigation in urothelial carcinoma, with promising results [66] - perhaps most exciting, responses in patients are often early, durable, and associated with expression of targeted relevant biomarkers (eg, PD-L1). These studies focusing on immunotherapy in urologic malignancy have been extensively reviewed elsewhere; the potential to define predictive biomarkers for these classes of agents remains an active area of investigation [67,68]. These approaches 
target the adaptive immune response and there are also other efforts targeting the innate immune response that may help develop better responses in nonresponders in combination with adaptive approaches.

\subsection{Lessons from outlier responders}

Exceptional responders-those patients whose cancers have an unusually robust and positive response to specific agents - can inform the biology of these diseases, highlight pathways for intervention, and define biomarkers for prediction of a therapeutic response. This approach has yielded results. In urothelial carcinoma, genome sequencing revealed that a patient with an exceptional response to everolimus harbored mutations in the mTOR and NF genes. These alterations were subsequently shown to impact the response of cancer cells to everolimus, nominating these alterations as potential biomarkers of response to $m T O R$ inhibition [69]. Similarly, a patient with metastatic prostate cancer with exceptional response to cisplatin (after suggestion of small cell morphology) was shown to have inactivation of the $F A N C A$ gene, a key component of DNA repair pathways modulating response to platinum-based chemotherapeutics [70]. These reports, while anecdotal in nature, underscore the potential utility in gaining mechanistic insight and defining predictive markers from outlier responders. Such reports also highlight another challenge—given that rare subsets of patients may respond exceptionally well to therapies that may be ineffective in a population as a whole, how do we establish the definition of a negative clinical trial? In the absence of pre-existing genomic information, the tails of negative trials, consisting of the most robust responders in the population, may harbor informative information regarding predictive biomarkers.

This idea has real importance as the field of precision medicine evolves in urologic oncology. Many distinct, legitimately targetable alterations, with currently available therapeutics of proven efficacy, exist in urologic malignancies. However, they may be exceptionally rare, and occur in only a few percent of patients, and across different types of malignancies rather than enriched in one type. Furthermore, consideration should be given to the clonal structure of the tumor and when the targetable somatic alteration occurs during the course of tumor evolution [71]. Targetable somatic alterations occurring early on in tumor evolution, within the trunk of the tumor's evolutionary tree, present in every cancer cell, may provide more robust biomarkers of tumor response than alterations such as the mTOR pathway in ccRCC; however, these are subject to tumor sampling bias, usually occurring within a cancer subclone, present in some tumor regions but not others [72]. It should also be borne in mind that large-scale alterations in whole or parts of chromosomes that are currently refractory to contemporary targeted therapy strategies, can also drive tumor progression. For instance, in papillary renal cancer driver gene mutations are often subclonal alterations, in contrast to large-scale chromosomal alterations that were found to be clonal in nature [73].

Now that comprehensive molecular profiling is available on multiple urologic malignancies, through The Cancer Genome Atlas, International Cancer Genome Consortium, and other efforts, clear examples of rare but clinically important alterations are emerging. Amplifications, activating mutations, and gene fusions in the kinase $B R A F$ (a common 
driver in melanoma and other cancers) occur in roughly $1-5 \%$ of prostate cancers-these may be targetable with currently available inhibitors [10,74-76]. Amplifications and mutations in ERRB2, encoding the growth factor receptor tyrosine kinase HER2/neu, are present in about $10 \%$ of muscle invasive bladder cancers [77-79] — these cancers may be susceptible to trastuzumab (Herceptin). Mutations in the epigenetic modifying enzyme IDH1, one of the most common mutations in gliomas, occur in about $1 \%$ of prostate cancers [10,75]. IDH1 mutation also represents an attractive target for therapy, with promising preclinical data [80]. These are just a few examples of alterations that have high promise as therapeutic targets, but are identified in only a small minority of patients. Highlighting the potential of this approach, the National Cancer Institute has embarked on the Exceptional Responders Initiative, a bedside to bench genomic approach to define the molecular underpinnings of rare but exceptional patient responses.

This raises an obvious concern: how can we possibly study a biomarker or target that occurs in only $1 \%$ of a given population? Understanding how to rigorously evaluate comparative treatment efficacy and patient responses in this new paradigm will be a critical challenge, given the limited number of patients with any one disease that may have the alterations of interest. One approach to this that has been suggested and now implemented is the idea of the basket trial-a novel form of clinical trial design that has emerged to meet the needs of the genomics era. The hypothesis underlying basket trials is that the molecular marker will predict tumor response to specific therapies across disease types. Such trials have generated considerable interest because they incorporate current information about genomics and precision medicine while promising the ability to identify favorable responses to targeted therapy with a relatively small number of patients. The National Cancer Institute Molecular Analysis for Therapy Choice trial is one prominent example of this approach. However, these come with their own unique limitations, including the need for prospectively collected, detailed (and expensive) molecular profiling data. In addition, the potential success of each basket trial is likely inextricably linked to the reliability of the target or marker in question and the specific therapy utilized. Unfortunately, not all therapies will hit the target in all cancer types, and not all cancers may respond the same way to effective blockade of all pathways. These complicating factors will likely continue force the evolution of clinical trial design.

\section{Conclusions}

Major advances have been made in cataloguing the genomic, transcriptomic, proteomic, and epigenetic alterations across urologic malignances. We have an improved understanding of the molecular mechanisms underlying these diseases, and therapies aiming to leverage this knowledge continue to emerge. Critical steps going forward will be to refine the list of truly predictive biomarkers and therapeutic targets, and evaluate their impact in real-world clinical settings. The continuing evolution of clinical trial design must proceed with this process, as evaluation of novel agents, with novel predictors will require novel approaches to define the population to be treated, and define efficacy in that population. 


\section{Acknowledgments}

We are grateful to the individuals with cancer and their families for allowing us to care for them and learn from them. We thank the many collaborators whose long-time support, drive, and scientific curiosity have made these studies possible.

Funding/Support and role of the sponsor: This work was supported by the US National Cancer Institute (K08CA187417-02, 2R01CA125612-05A1), the Prostate Cancer Foundation, and the Urology Care Foundation (Rising Star in Urology Research Award to Christopher E. Barbieri).

\section{References}

1. Sridhar SS, Freedland SJ, Gleave ME, et al. Castration-resistant prostate cancer: from new pathophysiology to new treatment. Eur Urol. 2014; 65:289-99. [PubMed: 23957948]

2. Valenca LB, Sweeney CJ, Pomerantz MM. Sequencing current therapies in the treatment of metastatic prostate cancer. Cancer Treat Rev. 2015; 41:332-40. [PubMed: 25784591]

3. King CR, Kraus MH, Aaronson SA. Amplification of a novel $v$-erbB-related gene in a human mammary carcinoma. Science. 1985; 229:974-6. [PubMed: 2992089]

4. Slamon DJ, Clark GM, Wong SG, Levin WJ, Ullrich A, McGuire WL. Human breast cancer: correlation of relapse and survival with amplification of the HER-2/neu oncogene. Science. 1987; 235:177-82. [PubMed: 3798106]

5. Chapman PB, Hauschild A, Robert C, et al. Improved survival with vemurafenib in melanoma with BRAFV600E mutation. N Engl J Med. 2011; 364:2507-16. [PubMed: 21639808]

6. Barbieri CE, Bangma CH, Bjartell A, et al. The mutational landscape of prostate cancer. Eur Urol. 2013; 64:567-76. [PubMed: 23759327]

7. Vargas AJ, Harris CC. Biomarker development in the precision medicine era: Lung cancer as a case study. Nat Rev Cancer. 2016; 16:525-37. [PubMed: 27388699]

8. Sonpavde G, Attard G, Bellmunt J, et al. The role of abiraterone acetate in the management of prostate cancer: a critical analysis of the literature. Eur Urol. 2011; 60:270-8. [PubMed: 21550166]

9. Agarwal N, Sonpavde G, Sternberg CN. Novel molecular targets for the therapy of castrationresistant prostate cancer. Eur Urol. 2012; 61:950-60. [PubMed: 22209376]

10. Robinson D, Van Allen EM, Wu YM, et al. Integrative clinical genomics of advanced prostate cancer. Cell. 2015; 161:1215-28. [PubMed: 26000489]

11. Taplin M-E, Bubley GJ, Ko Y-J, et al. Selection for androgen receptor mutations in prostate cancers treated with androgen antagonist. Cancer Res. 1999; 59:2511-5. [PubMed: 10363963]

12. Taplin M-E, Bubley GJ, Shuster TD, et al. Mutation of the androgen-receptor gene in metastatic androgen-independent prostate cancer. N Engl J Med. 1995; 332:1393-8. [PubMed: 7723794]

13. Visakorpi T, Hyytinen E, Koivisto P, et al. In vivo amplification of the androgen receptor gene and progression of human prostate cancer. Nat Genet. 1995; 9:401-6. [PubMed: 7795646]

14. Azad AA, Volik SV, Wyatt AW, et al. Androgen receptor gene aberrations in circulating cell-free DNA: biomarkers of therapeutic resistance in castration-resistant prostate cancer. Clin Cancer Res. 2015; 21:2315-24. [PubMed: 25712683]

15. Azad AA, Volik SV, Wyatt AW, et al. Androgen receptor gene aberrations in circulating cell-free DNA: Biomarkers of therapeutic resistance in castration-resistant prostate cancer. Clin Cancer Res. 2015; 21:2315-24. [PubMed: 25712683]

16. Salvi S, Casadio V, Conteduca V, et al. Circulating cell-free $A R$ and $C Y P 17 A 1$ copy number variations may associate with outcome of metastatic castration-resistant prostate cancer patients treated with abiraterone. Br J Cancer. 2015; 112:1717-24. [PubMed: 25897673]

17. Li Y, Chan SC, Brand LJ, Hwang TH, Silverstein KA, Dehm SM. Androgen receptor splice variants mediate enzalutamide resistance in castration-resistant prostate cancer cell lines. Cancer Res. 2013; 73:483-9. [PubMed: 23117885]

18. Antonarakis ES, Lu C, Wang H, et al. AR-V7 and resistance to enzalutamide and abiraterone in prostate cancer. N Engl J Med. 2014; 371:1028-38. [PubMed: 25184630] 
19. Nakazawa M, Lu C, Chen Y, et al. Serial blood-based analysis of AR-V7 in men with advanced prostate cancer. Ann Oncol. 2015; 26:1859-65. [PubMed: 26117829]

20. Epstein JI, Amin MB, Beltran H, et al. Proposed morphologic classification of prostate cancer with neuroendocrine differentiation. Am J Surg Pathol. 2014; 38:756-67. [PubMed: 24705311]

21. Beltran H, Tomlins S, Aparicio A, et al. Aggressive variants of castration-resistant prostate cancer. Clin Cancer Res. 2014; 20:2846-50. [PubMed: 24727321]

22. Beltran H, Prandi D, Mosquera JM, et al. Divergent clonal evolution of castration-resistant neuroendocrine prostate cancer. Nat Med. 2016; 22:298-305. [PubMed: 26855148]

23. Beltran H, Rickman DS, Park K, et al. Molecular characterization of neuroendocrine prostate cancer and identification of new drug targets. Cancer Discov. 2011; 1:487-95. [PubMed: 22389870]

24. Kim WY, Kaelin WG. Role of VHL gene mutation in human cancer. J Clin Oncol. 2004; 22:49915004. [PubMed: 15611513]

25. Escudier B, Pluzanska A, Koralewski P, et al. Bevacizumab plus interferon alfa-2a for treatment of metastatic renal cell carcinoma: a randomised, double-blind phase III trial. Lancet. 2007; 370:2103-11. [PubMed: 18156031]

26. Rini BI, Halabi S, Rosenberg JE, et al. Bevacizumab plus interferon alfa compared with interferon alfa monotherapy in patients with metastatic renal cell carcinoma: CALGB 90206. J Clin Oncol. 2008; 26:5422-8. [PubMed: 18936475]

27. Escudier B, Eisen T, Stadler WM, et al. Sorafenib in advanced clear-cell renal-cell carcinoma. N Engl J Med. 2007; 356:125-34. [PubMed: 17215530]

28. Rini BI, Michaelson MD, Rosenberg JE, et al. Antitumor activity and biomarker analysis of sunitinib in patients with bevacizumab-refractory metastatic renal cell carcinoma. J Clin Oncol. 2008; 26:3743-8. [PubMed: 18669461]

29. Escudier B, Eisen T, Stadler WM, et al. Sorafenib for treatment of renal cell carcinoma: Final efficacy and safety results of the phase III treatment approaches in renal cancer global evaluation trial. J Clin Oncol. 2009; 27:3312-8. [PubMed: 19451442]

30. Escudier B, Szczylik C, Hutson TE, et al. Randomized phase II trial of first-line treatment with sorafenib versus interferon Alfa-2a in patients with metastatic renal cell carcinoma. J Clin Oncol. 2009; 27:1280-9. [PubMed: 19171708]

31. Rini BI, Wilding G, Hudes G, et al. Phase II study of axitinib in sorafenib-refractory metastatic renal cell carcinoma. J Clin Oncol. 2009; 27:4462-8. [PubMed: 19652060]

32. Choueiri TK, Vaziri SAJ, Jaeger E, et al. von Hippel-Lindau gene status and response to vascular endothelial growth factor targeted therapy for metastatic clear cell renal cell carcinoma. J Urol. 2008; 180:860-6. [PubMed: 18635227]

33. Youssif TA, Fahmy MA, Koumakpayi IH, et al. The mammalian target of rapamycin pathway is widely activated without PTEN deletion in renal cell carcinoma metastases. Cancer. 2011; 117:290-300. [PubMed: 20830770]

34. Cancer Genome Atlas Research Network. Comprehensive molecular characterization of clear cell renal cell carcinoma. Nature. 2013; 499:43-9. [PubMed: 23792563]

35. Gerlinger M, Rowan AJ, Horswell S, et al. Intratumor heterogeneity and branched evolution revealed by multiregion sequencing. N Engl J Med. 2012; 366:883-92. [PubMed: 22397650]

36. Gerlinger M, Horswell S, Larkin J, et al. Genomic architecture and evolution of clear cell renal cell carcinomas defined by multiregion sequencing. Nat Genet. 2014; 46:225-33. [PubMed: 24487277]

37. Motzer RJ, Hudes GR, Curti BD, et al. Phase I/II trial of temsirolimus combined with interferon alfa for advanced renal cell carcinoma. J Clin Oncol. 2007; 25:3958-64. [PubMed: 17761980]

38. Hudes G, Carducci M, Tomczak P, et al. Temsirolimus, interferon alfa, or both for advanced renalcell carcinoma. N Engl J Med. 2007; 356:2271-81. [PubMed: 17538086]

39. Motzer RJ, Escudier B, Oudard S, et al. Efficacy of everolimus in advanced renal cell carcinoma: a double-blind, randomised, placebo-controlled phase III trial. Lancet. 2008; 372:449-56. [PubMed: 18653228]

40. Bissler JJ, McCormack FX, Young LR, et al. Sirolimus for angiomyolipoma in tuberous sclerosis complex or lymphangioleiomyomatosis. N Engl J Med. 2008; 358:140-51. [PubMed: 18184959] 
41. Bissler JJ, Kingswood JC, Radzikowska E, et al. Everolimus for angiomyolipoma associated with tuberous sclerosis complex or sporadic lymphangioleiomyomatosis (EXIST-2): a multicentre, randomized, double-blind, placebo-controlled trial. Lancet. 2013; 381:817-24. [PubMed: 23312829]

42. El-Hashemite N, Zhang H, Henske EP, Kwiatkowski DJ. Mutation in TSC2 and activation of mammalian target of rapamycin signalling pathway in renal angiomyolipoma. Lancet. 2003; 361:1348-9. [PubMed: 12711473]

43. Witjes JA, Comperat E, Cowan NC, et al. EAU guidelines on muscle-invasive and metastatic bladder cancer: Summary of the 2013 guidelines. Eur Urol. 2014; 65:778-92. [PubMed: 24373477]

44. International Collaboration of Trialists; Medical Research Council Advanced Bladder Cancer Working Party (now the National Cancer Research Institute Bladder Cancer Clinical Studies Group); European Organization for Research and Treatment of Cancer Genito-Urinary Tract Cancer Group. et al. International Phase III Trial Assessing Neoadjuvant Cisplatin, Methotrexate, and Vinblastine Chemotherapy for Muscle-Invasive Bladder Cancer: Long-Term Results of the BA06 30894 Trial. J Clin Oncol. 2011; 29:2171-7. [PubMed: 21502557]

45. Grossman HB, Natale RB, Tangen CM, et al. Neoadjuvant Chemotherapy plus cystectomy compared with cystectomy alone for locally advanced bladder cancer. N Engl J Med. 2003; 349:859-66. [PubMed: 12944571]

46. Advanced Bladder Cancer Meta-analysis Collaboration. Neoadjuvant chemotherapy in invasive bladder cancer: A systematic review and meta-analysis. Lancet. 2003; 361:1927-34. [PubMed: 12801735]

47. Winquist E, Kirchner TS, Segal R, Chin J, Lukka H. Neoadjuvant chemotherapy for transitional cell carcinoma of the bladder: A systematic review and meta-analysis. J Urol. 2004; 171:561-9. [PubMed: 14713760]

48. Advanced Bladder Cancer (ABC) Meta-analysis Collaboration. Neoadjuvant chemotherapy in invasive bladder cancer: update of a systematic review and meta-analysis of individual patient data advanced bladder cancer (ABC) meta-analysis collaboration. Eur Urol. 2005; 48:202-5. discussion 5-6. [PubMed: 15939524]

49. Niegisch G, Lorch A, Droller MJ, Lavery HJ, Stensland KD, Albers P. Neoadjuvant chemotherapy in patients with muscle-invasive bladder cancer: which patients benefit? Eur Urol. 2013; 64:355-7. [PubMed: 23773558]

50. Malats N, Bustos A, Nascimento CM, et al. P53 as a prognostic marker for bladder cancer: a metaanalysis and review. Lancet Oncol. 2005; 6:678-86. [PubMed: 16129368]

51. Van Allen EM, Mouw KW, Kim P, et al. Somatic ERCC2 mutations correlate with cisplatin sensitivity in muscle-invasive urothelial carcinoma. Cancer Discov. 2014; 4:1140-53. [PubMed: 25096233]

52. Plimack ER, Dunbrack RL, Brennan TA, et al. Defects in DNA repair genes predict response to neoadjuvant cisplatin-based chemotherapy in muscle-invasive bladder cancer. Eur Urol. 2015; 68:959-67. [PubMed: 26238431]

53. Yap KL, Kiyotani K, Tamura K, et al. Whole-exome sequencing of muscle-invasive bladder cancer identifies recurrent mutations of $U N C 5 C$ and prognostic importance of DNA repair gene mutations on survival. Clin Cancer Res. 2014; 20:6605-17. [PubMed: 25316812]

54. Al-Ahmadie H, Iyer G, Hohl M, et al. Synthetic lethality in ATM-deficient RAD50-mutant tumors underlies outlier response to cancer therapy. Cancer Discov. 2014; 4:1014-21. [PubMed: 24934408]

55. Groenendijk FH, de Jong J, Fransen van de Putte EE, et al. ERBB2 mutations characterize a subgroup of muscle-invasive bladder cancers with excellent response to neoadjuvant chemotherapy. Eur Urol. 2016; 69:384-8. [PubMed: 25636205]

56. Choi W, Porten S, Kim S, Willis D, et al. Identification of distinct basal and luminal subtypes of muscle-invasive bladder cancer with different sensitivities to frontline chemotherapy. Cancer Cell. 2014; 25:152-65. [PubMed: 24525232]

57. Mateo J, Carreira S, Sandhu S, et al. DNA-repair defects and olaparib in metastatic prostate cancer. N Engl J Med. 2015; 373:1697-708. [PubMed: 26510020] 
58. Cheng HH, Pritchard CC, Boyd T, Nelson PS, Montgomery B. Biallelic inactivation of BRCA2 in platinum-sensitive metastatic castration-resistant prostate cancer. Eur Urol. 2016; 69:992-5. [PubMed: 26724258]

59. Pritchard CC, Mateo J, Walsh MF, et al. Inherited DNA-repair gene mutations in men with metastatic prostate cancer. N Engl J Med. 2016; 375:443-53. [PubMed: 27433846]

60. Babjuk M, Burger M, Zigeuner R, et al. EAU guidelines on non-muscle-invasive urothelial carcinoma of the bladder: Update 2013. Eur Urol. 2013; 64:639-53. [PubMed: 23827737]

61. Ljungberg B, Cowan NC, Hanbury DC, et al. EAU guidelines on renal cell carcinoma: the 2010 update. Eur Urol. 2010; 58:398-406. [PubMed: 20633979]

62. Upton MP, Parker RA, Youmans A, McDermott DF, Atkins MB. Histologic predictors of renal cell carcinoma response to interleukin-2-based therapy. J Immunother. 2005; 28:488-95. [PubMed: 16113605]

63. Atkins M, Regan M, McDermott D, et al. Carbonic anhydrase IX expression predicts outcome of interleukin 2 therapy for renal cancer. Clin Cancer Res. 2005; 11:3714-21. [PubMed: 15897568]

64. Phan GQ, Attia P, Steinberg SM, White DE, Rosenberg SA. Factors associated with response to high-dose interleukin-2 in patients with metastatic melanoma. J Clin Oncol. 2001; 19:3477-82. [PubMed: 11481353]

65. Motzer RJ, Escudier B, McDermott DF, et al. Nivolumab versus everolimus in advanced renal-cell carcinoma. N Engl J Med. 2015; 373:1803-13. [PubMed: 26406148]

66. Powles T, Eder JP, Fine GD, et al. MPDL3280A (anti-PD-L1) treatment leads to clinical activity in metastatic bladder cancer. Nature. 2014; 515:558-62. [PubMed: 25428503]

67. Carosella ED, Ploussard G, LeMaoult J, Desgrandchamps F. A systematic review of immunotherapy in urologic cancer: Evolving roles for targeting of CTLA-4, PD-1/PD-L1, and HLA-G. Eur Urol. 2015; 68:267-79. [PubMed: 25824720]

68. Miao D, Van Allen EM. Genomic determinants of cancer immunotherapy. Curr Opin Immunol. 2016; 41:32-8. [PubMed: 27254251]

69. Iyer G, Hanrahan AJ, Milowsky MI, et al. Genome sequencing identifies a basis for everolimus sensitivity. Science. 2012; 338:221. [PubMed: 22923433]

70. Beltran H, Eng K, Mosquera JM, et al. Whole-exome sequencing of metastatic cancer and biomarkers of treatment response. JAMA Oncol. 2015; 1:466-74. [PubMed: 26181256]

71. McGranahan N, Favero F, de Bruin EC, Birkbak NJ, Szallasi Z, Swanton C. Clonal status of actionable driver events and the timing of mutational processes in cancer evolution. Sci Transl Med. 2015; 7:283ra54.

72. McGranahan N, Swanton C. Biological and therapeutic impact of intratumor heterogeneity in cancer evolution. Cancer Cell. 2015; 27:15-26. [PubMed: 25584892]

73. Kovac M, Navas C, Horswell S, et al. Recurrent chromosomal gains and heterogeneous driver mutations characterise papillary renal cancer evolution. Nat Commun. 2015; 6:6336. [PubMed: 25790038]

74. Baca SC, Prandi D, Lawrence MS, et al. Punctuated evolution of prostate cancer genomes. Cell. 2013; 153:666-77. [PubMed: 23622249]

75. Barbieri CE, Baca SC, Lawrence MS, et al. Exome sequencing identifies recurrent SPOP, FOXA1, and MED12 mutations in prostate cancer. Nat Genet. 2012; 44:685-9. [PubMed: 22610119]

76. Grasso CS, Wu YM, Robinson DR, et al. The mutational landscape of lethal castration-resistant prostate cancer. Nature. 2012; 487:239-43. [PubMed: 22722839]

77. Cancer Genome Atlas Research Network. Comprehensive molecular characterization of urothelial bladder carcinoma. Nature. 2014; 507:315-22. [PubMed: 24476821]

78. Iyer G, Al-Ahmadie H, Schultz N, et al. Prevalence and co-occurrence of actionable genomic alterations in high-grade bladder cancer. J Clinical Oncol. 2013; 31:3133-40. [PubMed: 23897969]

79. Kim PH, Cha EK, Sfakianos JP, et al. Genomic predictors of survival in patients with high-grade urothelial carcinoma of the bladder. Eur Urol. 2015; 67:198-201. [PubMed: 25092538]

80. Rohle D, Popovici-Muller J, Palaskas N, et al. An inhibitor of mutant IDH1 delays growth and promotes differentiation of glioma cells. Science. 2013; 340:626-30. [PubMed: 23558169] 
81. Kwon ED, Drake CG, Scher HI, et al. Ipilimumab versus placebo after radiotherapy in patients with metastatic castration-resistant prostate cancer that had progressed after docetaxel chemotherapy (CA184-043): A multicenter, randomized, double-blind, phase 3 trial. Lancet Oncol. 2014; 15:700-12. [PubMed: 24831977]

82. Rosenberg JE, Hoffman-Censits J, Powles T, et al. Atezolizumab in patients with locally advanced and metastatic urothelial carcinoma who have progressed following treatment with platinum-based chemotherapy: A single-arm, multicenter, phase 2 trial. Lancet. 2016; 387:1909-20. [PubMed: 26952546]

83. Escudier B, Pluzanska A, Koralewski P, et al. Bevacizumab plus interferon alfa-2a for treatment of metastatic renal cell carcinoma: a randomised, double-blind phase III trial. Lancet. 2008; 370:2103-11.

84. Rini BI, Michaelson MD, Rosenberg JE, et al. Antitumor activity and biomarker analysis of sunitinib in patients with bevacizumab-refractory metastatic renal cell carcinoma. J Clin Oncol. 2008; 26:3743-8. [PubMed: 18669461]

85. Escudier B, Eisen T, Stadler WM, et al. Sorafenib for treatment of renal cell carcinoma: final efficacy and safety results of the phase III treatment approaches in renal cancer global evaluation trial. J Clin Oncol. 2009; 27:3312-8. [PubMed: 19451442]

86. Cho D, Signoretti S, Dabora S, et al. Potential histologic and molecular predictors of response to temsirolimus in patients with advanced renal cell carcinoma. Clin Genitourin Cancer. 2007; 5:37985. [PubMed: 17956710]

87. Motzer RJ, Escudier B, McDermott DF, et al. Nivolumab versus everolimus in advanced renal-cell carcinoma. N Engl J Med. 2015; 373:1803-13. [PubMed: 26406148]

88. Taube JM, Klein A, Brahmer JR, et al. Association of PD-1, PD-1 ligands, and other features of the tumor immune microenvironment with response to anti-PD-1 therapy. Clin Cancer Res. 2014; 20:5064-74. [PubMed: 24714771] 


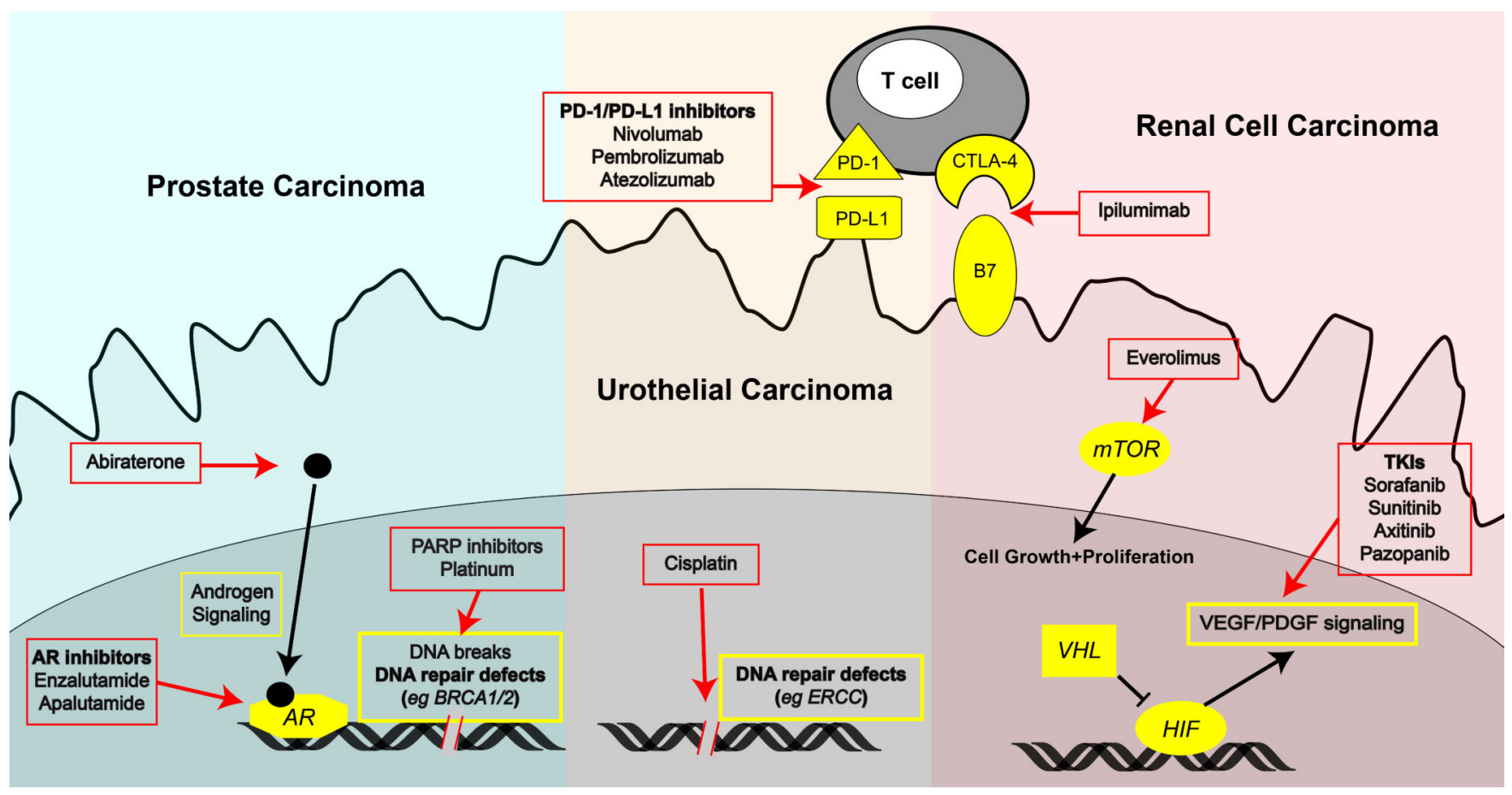

Fig. 1.

Landscape of precision urologic oncology. Relevant biological pathways, therapeutic targets, and therapies are highlighted for prostate cancer (left), urothelial cancer (center), and renal cell carcinoma (right). Therapeutics are outlined in red; biological pathways and targets are shown in yellow. Immunotherapy approaches using checkpoint inhibitors (top) may be applicable across disease histologies, with the most current evidence in renal and urothelial cancer. AR = androgen receptor; CTLA-4 = cytotoxic T-lymphocyte-associated protein 4; $\mathrm{mTOR}=$ mechanistic target of rapamycin; PD-1 = programmed cell death protein 1; PDGF $=$ platelet-derived growth factor; $\mathrm{PD}-\mathrm{L} 1=$ programmed death-ligand 1 ; TKIs $=$ tyrosine kinase inhibitors; VEGF = vascular endothelial growth factor. 
Table 1

Summary of potential biomarker directed therapy across urologic oncology

\begin{tabular}{|c|c|c|c|}
\hline \multicolumn{4}{|l|}{ Prostate cancer } \\
\hline Therapy & Mechanism of action & Potential biomarkers & References \\
\hline $\begin{array}{l}\text { AR-directed agents } \\
\text { Enzalutamide } \\
\text { Abiraterone } \\
\text { Apalutamide }\end{array}$ & $\begin{array}{l}\text { Inhibition of androgen receptor } \\
\text { signaling }\end{array}$ & $\begin{array}{l}\text { Androgen receptor mutations/amplifications } \\
\text { AR-V7 }\end{array}$ & $\begin{array}{l}\text { Azad et al } 2015[14] \\
\text { Azad et al } 2015[15] \\
\text { Salvi et al } 2015[16] \\
\text { Li et al } 2013[17]\end{array}$ \\
\hline $\begin{array}{l}\text { DNA damaging agents } \\
\text { PARP inhibitors } \\
\text { (olaparib) } \\
\text { Platinum } \\
\text { chemotherapy (cisplatin, } \\
\text { carboplatin) }\end{array}$ & $\begin{array}{l}\text { Induction of double strand } \\
\text { DNA breaks }\end{array}$ & Defects in DNA repair genes-BRCA1/2, $A T M$ & $\begin{array}{l}\text { Robinson et al } 2015[10] \\
\text { Mateo et al } 2015[57] \\
\text { Cheng et al } 2016[58]\end{array}$ \\
\hline AURKA inhibitors & Aurora kinase inhibition & $\begin{array}{l}\text { NEPC; AURKA upregulation; increased N-myc } \\
\text { signaling }\end{array}$ & Beltran et al 2011 [23] \\
\hline $\begin{array}{l}\text { CTLA-4 inhibitor } \\
\text { Ipilumimab }\end{array}$ & $\begin{array}{l}\text { Antibody blocking the T-cell } \\
\text { checkpoint receptor CTLA-4, } \\
\text { resulting in improved immune } \\
\text { surveillance }\end{array}$ & & Kwon et al 2014 [81] \\
\hline
\end{tabular}

\begin{tabular}{|l|l|l|l|}
\hline Urothelial carcinoma & Mechanism of action & Potential biomarkers & References \\
\hline Therapy & $\begin{array}{l}\text { Induction of double strand } \\
\text { DNA breaks (and other damage) }\end{array}$ & $\begin{array}{l}\text { DNA repair defects: ERCC2 } \\
\text { mutations } \\
\text { ATM, RB, FANCC alterations } \\
\text { ERBB2 mutations }\end{array}$ & $\begin{array}{l}\text { Van Allen et al 2014 [51] } \\
\text { Groenendijk et al 2015 [55] } \\
\text { Plimack et al 2015 [52] }\end{array}$ \\
$\begin{array}{l}\text { Platinum chemotherapy } \\
\text { Cisplatin containing } \\
\text { regimens: MVAC, GC }\end{array}$ & $\begin{array}{l}\text { PD-L1 } \\
\text { High mutational load }\end{array}$ & $\begin{array}{l}\text { Powles et al 2014 [66] } \\
\text { Rosenberg et al 2016 [82] }\end{array}$ \\
\hline $\begin{array}{l}\text { PD-1/PD-L1 inhibitors } \\
\text { Nivolumab } \\
\text { Pembrolizumab } \\
\text { Atezolizumab }\end{array}$ & sesulting in improved immune & & \\
\hline
\end{tabular}

\begin{tabular}{|c|c|c|c|}
\hline \multicolumn{4}{|l|}{ Renal cell carcinoma } \\
\hline Therapy & Mechanism of action & Potential biomarkers & References \\
\hline $\begin{array}{l}\text { Anti-VEGF } \\
\text { Bevacizumab }\end{array}$ & Monoclonal antibody against VEGF & VEGF and VEGF related proteins & $\begin{array}{l}\text { Escudier et al } 2008 \text { [83] } \\
\text { Rini et al } 2008 \text { [84] }\end{array}$ \\
\hline $\begin{array}{l}\text { Tyrosine kinase inhibitors } \\
\text { Sunitinib } \\
\text { Sorafanib } \\
\text { Pazopanib } \\
\text { Axitinib }\end{array}$ & $\begin{array}{l}\text { Inhibition of receptor tyrosine kinases } \\
\text { downstream of VHL/HIF-1: VEGFR, PDGFR, } \\
\text { etc. }\end{array}$ & VEGF and VEGF related proteins & $\begin{array}{l}\text { Rini et al } 2008 \text { [84] } \\
\text { Escudier et al } 2009 \text { [85] }\end{array}$ \\
\hline $\begin{array}{l}\text { mTOR inhibitors } \\
\text { Temsirolimus } \\
\text { Everolimus }\end{array}$ & Inhibition of mTOR & mTOR activity (P-S6) & Cho et al 2007 [86] \\
\hline $\begin{array}{l}\text { PD-1/PD-L1 inhibitors } \\
\text { Nivolumab } \\
\text { Pembrolizumab } \\
\text { Atezolizumab }\end{array}$ & $\begin{array}{l}\text { Targeting PD-1/PD-L1 interaction resulting in } \\
\text { improved immune surveillance }\end{array}$ & $\begin{array}{l}\text { PD-L1 } \\
\text { High mutational load }\end{array}$ & $\begin{array}{l}\text { Motzer et al } 2015[87] \\
\text { Taube et al } 2014[88]\end{array}$ \\
\hline
\end{tabular}

$\mathrm{AR}=$ androgen receptor; AURKA = aurora kinase A; CTLA-4 = cytotoxic T-lymphocyte-associated protein 4; GC = gemcitabine and cisplatin; $\mathrm{mTOR}=$ mechanistic target of rapamycin; $\mathrm{MVAC}=$ methotrexate, vinblastine, doxorubicin, cisplatin; $\mathrm{NEPC}=$ neuroendocrine prostate cancer; $\mathrm{PARP}=$ polyadenosine diphosphate ribose polymerase; PD-1 = programmed cell death protein $1 ; \mathrm{PD}-\mathrm{L} 1=$ programmed death-ligand $1 ; \mathrm{VEGF}=$ vascular endothelial growth factor. 